\title{
LOS IMPRESOS CASTELLANOS DE SÉNECA Y SU CONTEXTO EUROPEO*
}

\author{
Juan Miguel Valero Moreno \\ Universidad de Salamanca - IEMYRhd \\ asmodeo@usal.es
}

\section{Prolegómenos}

No arriesgo demasiado si apuesto a que el primero entre los libros que marcaron un hito perdurable en la historia de la literatura castellana por mor de su difusión impresa, y no en virtud de su (exigua) vida manuscrita, fue la Comedia de Calixto y Melibea ${ }^{1}$. Fue clave del éxito no solo su reconocida originalidad artística, sino también su contemporaneidad con el auge de la

* Este trabajo se inscribe en el marco del proyecto de investigación Alfonso de Cartagena. Obras Completas FFI 2014-55902-P y FFI 2017-84858-P (MINECO y MICINN, Gobierno de España). Una primera versión del mismo fue presentada en el Coloquio Internacional Los clásicos latinos en los orígenes de la imprenta: textos, contextos y cultura impresa (ca. 1450-1540), Madrid, Universidad Nacional de Educación a Distancia, 19-21 de noviembre de 2014. Las páginas que presento ahora no pretenden ser más que una aproximación, muy parcial (y complementaria a otras líneas abiertas) a las dificultades que presentan los impresos de las versiones castellanas de Séneca.

${ }^{1}$ La transmisión textual de La Celestina queda limpiamente deslindada, hasta donde se ha podido avanzar, por Francisco J. Lobera y Francisco Rico (Fernando de Rojas, La Celestina, Madrid, Real Academia Española, 2001, pp. 518-549. Para la Comedia de Calisto y Melibea son fundamento los impresos de Burgos, Fadrique de Basilea, 1499-1502; Toledo, Pedro Hagenbach, 1500 y Sevilla, Estanislao Polono, 1501, además del manuscrito II-1520 de la Real Biblioteca (Madrid), que contiene un fragmento del auto I de la Comedia «poco menos que inutilizable para el texto crítico ([...]) porque es patente que se trataría de un original descartado por Rojas a favor de otro, el original harto distinto seguido en la Comedia» (ed. cit., p. 541). Para las discusiones en torno al texto del manuscrito desde su descubrimiento por Charles B. Faulhaber, véase Juan Carlos Conde, «1989-1999: Diez años de La Celestina, manuscrito de Palacio», en Los orígenes del español y los grandes textos medievales: Mio Cid, Buen Amor y Celestina, ed. de Manuel Criado de Val, Madrid, CSIC, 2001, pp. 265-288; para los impresos primitivos de La Celestina (reales, imaginarios e hipotéticos), el excelente trabajo, presentado en 2002 y publicado por vez primera en 2007, de Víctor Infantes, «El laberinto cronológico y editorial de las primitivas impresiones de Celestina (14971514). Con una Marginalia bibliographica al cabo», en La trama impresa de «Celestina». Ediciones, libros y autógrafos de Fernando de Rojas, Madrid, Visor, 2010, pp. 11-103. 
imprenta en Castilla. El mismo texto se nutre ya, para la multitud de sentencias, muchas de ellas de origen senecano, que salen de las bocas de sus dramatis personce, de textos impresos y de sus aparatos específicos, como los índices rerum, loci, etc., que facilitaban su consulta ${ }^{2}$. La Comedia se constituyó, pues, en gran medida, como otros textos de menor relieve histórico, la Repetición de amores (c. 1497) de Lucena, por ejemplo, como un producto editorial vinculado a un determinado ambiente; en su caso, el universitario ${ }^{3}$.

A tal derrotero no fueron ajenos numerosos textos literarios de transición, a este respecto, de la época de los Reyes Católicos (por seguir el marbete de Keith Whinnom), que se incorporaron, y disfrutaron de eco futuro, a una vida editorial: la Vita Christi de Mendoza, la Cárcel de amor de Diego de San Pedro, el Cancionero de Juan del Enzina [...] $)^{4}$. Subrayo estos textos ahora,

${ }^{2}$ Barbara Riss y John Kevin Walsh, «Pero Díaz de Toledo’s Proverbios de Seneca and the Composition of Celestina», en Celestinesca, 11:1 (1987), pp. 3-12, llamaron la atención sobre la presencia de la antología glosada de Díaz de Toledo, cuya fuente principal son los Proverbia latinos de Publilio Siro. Louise Fothergill-Payne, Seneca and "Celestina», Cambridge, Cambridge University Press, 1988, pp. 26-44, subrayó, de inmediato, la importancia de los Cinco libros de Séneca de Alfonso de Cartagena y los Proverbios de Séneca de Pero Díaz de Toledo como trasfondo directo o indirecto de la sabiduría senequista en La Celestina. Caso paralelo es el que presentó Íñigo Ruiz Arzálluz, «El mundo intelectual del 'antiguo autor': las Auctoritates Aristotelis en la Celestina primitiva», en Boletín de la Real Academia Española, 76 (1996), pp. 265-284. Por no mencionar la incorporación de sententiae petrarquescas derivadas del índice de sus Opera impresas en Basilea en 1496, que levantó Florentino Castro Guisasola, Observaciones sobre las fuentes literarias de La Celestina, Madrid, CSIC, 1924, y estudió en profundidad Alan D. Deyermond, The Petrarchan Sources of La Celestina, Oxford, Oxford University Press, 1961. Para una historia cultural de los índices ( «guide per non leggere», entre otros usos), es clave el libro de Maria Gioia Tavoni, Circumnavigare il testo. Gli indici in età moderna, Nápoles, Liguori, 2009; y Claudio Leonardi, Marcello Morelli y Francesco Santi (eds.), Fabula in tabula: una storia degli indici dal manoscritto al testo elettronico, Spoleto, Centro Italiano di Studi sull'Alto Medioevo, 1995.

${ }^{3}$ Así se entiende en su más reciente y mejor edición, Lucena, Repetición de amores, ed. de Fernando Gómez Redondo, Alcalá de Henares, Universidad de Alcalá, 2014.

${ }^{4}$ Para el caso de las distintas versiones o recensiones de la Vita Christi de Mendoza (pero también para Diego de San Pedro), veáse Dorothy S. Severin, Del manuscrito a la imprenta en la época de Isabel la Católica, Kassel, Edition Reichenberger, 2004; para un caso a la inversa, M. ${ }^{a}$ Jesús Díez Garretas, «El cancionero ML1, copia manuscrita de un impreso: las Coplas de vita Christi de fray Íñigo de Mendoza», en Del impreso al manuscrito en los cancioneros, ed. de Josep Lluís Martos, Alcalá de Henares, Centro de Estudios Cervantinos, 2011, pp. 73-112; para la exitosa vida editorial de Cárcel de amor, con toda la bibliografía anterior pertinente, el estudio de M. ${ }^{a}$ Carmen Marín Pina, «La trayectoria editorial de la Cárcel de amor en el siglo xvI: avatares en la imprenta», en La literatura medieval hispánica en la imprenta (1475-1600), Valencia, Universidad de Valencia, 2016, pp. 151-172; en cuanto a Juan del Encina, siguen vigentes las perspectivas complementarias mantenidas por Vicenç Beltrán, «Tipología y génesis de los cancioneros. El Cancionero de Juan del Encina y los cancioneros de autor», en Humanismo y literatura en tiempos de Juan del Encina, ed. de Javier Guijarro Ceballos, Salamanca, Universidad de Salamanca, 1999, pp. 27-53 y Víctor Infantes, «Hacia la poesía impresa. Los pliegos sueltos de Juan del Encina: entre el cancionero manuscrito y el libro poético», en el mismo lugar (pp. 83-99), pero luego en Juan Carlos Conde y Víctor Infantes, De cancioneros manuscritos y poesía impresa. Estudios bibliográficos y literarios sobre lírica castellana del siglo XV, Madrid, Arco, 2007, pp. 191-212. Conviene tener ahora en cuenta el libro de Josep Lluís Martos, La poesía en la imprenta antigua, Alicante, Universidad de Alicante, 2014. 
y no el gran caudal de la prosa y la poesía anterior a los Reyes Católicos, por cuanto en este último periodo el paso del manuscrito al impreso, cuando lo hubo, fue necesariamente más breve, sin tiempo apenas para el desarrollo de más complejas y abundantes transmisiones manuscritas. Lo que no quiere decir, sin embargo, que no pocos de estos textos finiseculares no se muestren muy activos en las fases más tempranas de su transmisión textual, como es buena muestra la Vita Christi mencionada. El impulso y la relativa homogeneización de la imprenta a estas incipientes tradiciones, con todo, supuso, como es sabido, un poderoso agente de cambio cultural ${ }^{5}$.

En Castilla, de manera más destacada que en otras geografías europeas, la simbiosis entre la estricta modernidad literaria y su canalización impresa tuvo un carácter fulminante, por lo que una tipobibliografía comparada muestra, para un reino donde la implantación de la imprenta fue algo tardía, una casi inmediata conciencia y adaptación del cambio de canal, alimentada por autores e impresores 6 .

La literatura contemporánea (y sus más célebres antecedentes) se incluyeron de buena voluntad en programas editoriales que, a primera vista y comparados con proyectos como el de Aldo Manuzio en el emporio veneciano, parecen poco orgánicos y hasta desestructurados, sin que pueda hablarse en propiedad de la pretensión firme de la creación de un fondo específico o una idea pionera de catálogo editorial, pese a que, en casos concretos, pudiera hablarse de una relativa especialización?

\footnotetext{
${ }^{5}$ En la actualidad, y con un criterio amplio en cuanto a la consideración de lo literario, se encuentra en proceso de elaboración el Catálogo de obras medievales impresas en castellano hasta 1600 [en línea], cuyos antecedentes quedan descritos en Juan Manuel Cacho Blecua, «Hacia un catálogo de los textos medievales impresos (COMEDIC): el ejemplo de la Crónica popular del Cid», en Texto, edición y público lector en los albores de la imprenta, ed. de Marta Haro Cortés y José Luis Canet, Valencia, Universidad de Valencia, 2014, pp. 29-52 (en especial, pp. 29-37). Para el corpus capital de la literatura devocional y del espíritu, véase Rafael M. Pérez García, La imprenta y la literatura espiritual castellana en la España del Renacimiento (1470-1560), Gijón, Trea, 2006. Espero que no resulte ocioso convocar aquí de nuevo el estudio de Elisabeth L. Eisenstein, The Printing Press as an Agent of Change: Communications and Cultural Transformations in Early-Modern Europe, Cambridge Cambridge University Press, 1979, 2 vols., en particular su sección 2.3, «A classical revival reoriented: the two phases of the Renaissance». Véase la versión abreviada, introducida y traducida por Fernando Jesús Bouza Álvarez, La revolución de la imprenta en la Edad Moderna europea, Madrid, Akal, 1994, capítulo quinto.

${ }^{6}$ Téngase a la vista lo dicho a este propósito por Pedro M. Cátedra y María Luisa López Vidriero, $L a$ imprenta y su impacto en Castilla, Salamanca, Cervantes, 1998, pp. 76-79.

${ }^{7}$ Han de tenerse en cuenta, naturalmente, las limitaciones ya señaladas para el siglo xv por Keith Whinnom, Spanish Literary Historiography: Three Forms of Distortion, Exeter, University of Exeter, 1967, no tanto por la parquedad del catálogo de obras literarias medievales impresas en la etapa incunable cuanto por la conexión con la segunda cuestión a dilucidar («What is a classic?»; p. 13) y el énfasis de Whinnom a propósito de las confluencias entre literatura latina y romance medieval. A este respecto es importante el aviso (p. 11, n. 1) al libro de Ernst Philip Goldschmidt, Medieval Texts and their First Appearance in Print, Londres, Bibliographical Society, 1943, que apenas hace referencia a la Península
} 
Entonces, como en realidad fue general en Europa en la etapa anterior a 1500, y si nos olvidamos de la empresa cultural de Aldo, las ediciones de los clásicos latinos y griegos fueron surgiendo en Castilla, si no de manera improvisada, sí, en cierta medida, al albur de las nuevas necesidades y, como si dijéramos, bajo demanda ${ }^{8}$.

Es conocido que fueron los grandes centros universitarios o académicos de Europa los que hicieron de reclamo a esta específica tarea editorial que, con el andar del tiempo, dio lugar a la síntesis moderna de la tradición clásica y cristiana, ofreciendo modelos intelectual y materialmente homogéneos para textos clásicos y de los padres de la Iglesia, por ejemplo, y consolidando así las modernas humanidades que tuvieron en Petrarca su emblemático precursor ${ }^{9}$.

Hacia la segunda mitad de la década de los 30 del siglo XVI, coincidiendo con los estertores del Séneca castellano impreso de tradición medieval, los almacenes de las compañías de libreros, tal como puso de relieve Vicente Bécares para el caso salmantino, dan buena cuenta del tráfico intenso organizado en torno a las ediciones de los clásicos y, desde luego, de sus escolios y comentarios ${ }^{10}$. La mayor parte de los textos que contienen al Séneca latino se importaban entonces de Alemania y Francia para abastecer el mercado universitario. Resultaban privilegiadas las colecciones de obras bajo títulos genéricos como Opera Seneca, y también las Tragedias (en buena parte en

Ibérica. En cuanto al proyecto aldino, apuntó a la dirección que aquí se sugiere el libro de Martin Lowry, The World of Aldus Manutius: Bussines and scholarship in Renaissance Venice, Ithaca, Cornell University Press, 1979. En general, para el periodo que nos importa, véase Brian Richardson, Print Culture in Renaissance Italy. The Editor and the Vernacular Text, 1470-1600, Cambridge, Cambridge University Press, 1994; y, del mismo, Printing, Writers and Readers in Renaissance, Cambridge, Cambridge University Press, 1999. De particular interés me parecen las contribuciones de Paola Vecchi, «Aldo e il libro italiano: l'invenzione del lettore» y «Una identità culturale: i libri in volgare», en Nel Segno di Aldo. Nel V Centenario della scomparsa 1515-2015, ed. de Loredana Chines, Francesco Citti, Piero Scapecchi, Paolo Tinti y Paola Vecchi Galli, Bolonia, Pàtron Editore, 2015.

${ }^{8}$ Cfr. Carlos Clavería, «Quintiliano, Virgilio y Horacio no son negocio: la imprenta española en el siglo XVI», en Criticón, 65 (1995), pp. 5-15, y la posición que propone, a partir de ahí, Alejandro Coroleu, «A Note on the Circulation of Virgil's Eclogues in Renaisance Spain, 1496-1601», en Bulletin of Hispanic Studies, 93:10 (2016), pp. 123-134.

${ }^{9}$ Buen ejemplo de ello pudiera ser el comentario de Nebrija a Prudencio, Aurelii Prudentii Clementis V. C. Libelli cum commento Antonii Nebrissensis, ed. de Felipe González Vega, Salamanca, Universidad de Salamanca, 2002.

${ }^{10}$ Vicente Bécares Botas, La Compañia de libreros de Salamanca (1530-1534), Salamanca, Seminario de Estudios Medievales y Renacentistas, 2003, con numerosas entradas: p. 42, 519, Tragedia de Séneca yn 8; p. 55, 146 (3), Opera Senece; p. 68, 305 (10), Declamationes Senecae Alem.; p. 82, 781 (51), Opera Senece; p. 83, 835 (10), Opera Seneca Alem.; p. 93, 1154 (20), Tragedie Senece; p. 141, 173 (15), Tragedie Senece parve; p. 171, 839 (6), Eplas. de Séneca (y, más arriba, 826, la misma cantidad de Proverbios de Séneca); p. 272, 1914 (5), Libros de Sénica [sic] (y más abajo, 1943, doce Çelestinas). El segundo número es el de la serie documental, los números entre paréntesis se corresponden con ejemplares en almacén, y van acompañados en los distintos documentos por otros datos adicionales, aunque no de manera regular, como precio, procedencia, tamaño, etc. 
formatos breves, como el $8^{\circ}$ ) que cumplían con una función pedagógica diferenciada a la de la filosofía moral que correspondía al conjunto de los tratados senecanos, en folio o a veces en cuarto. Esta distinción, en todo caso, no resultaba nueva, sino que ya Alfonso de Cartagena había discriminado la función poética de las tragedias de la cognoscitiva y moral de los tratados ${ }^{11}$.

No es extraño, entonces, que en este mismo contexto los libreros salmantinos atesoraran, aunque en menor número que las obras latinas (de las cuales almacenaban más de cien ejemplares en los asientos conocidos) el Séneca castellano en romance, tanto las Epístolas (se entiende que la versión auspiciada por Fernán Pérez de Guzmán) como los Libros de Sénica, que por fuerza deberían corresponderse con Los cinco libros de Séneca que remontan a la traducción de Alfonso de Cartagena.

Los impresos latinos y griegos, vinculados a la cultura universitaria, se vieron acompañados por todo un cuerpo de subsidia (diccionarios, gramáticas, glosarios) y satélites (traducciones, paráfrasis, compendios o florilegios) tanto en lengua latina como vernácula, sin la consideración de los cuales no es posible comprender cabalmente el desarrollo de sus tradiciones ni la dimensión histórica de su recepción ${ }^{12}$.

Aquellos textos que procedían del rico fondo romancístico de la Edad Media, más algunas versiones surgidas al calor de la imprenta no resultaron, al menos en Castilla, productos marginales respecto a la lectura directa de los clásicos, sino que ocuparon un puesto más que relevante en la formación de los lectores de ámbitos no solo técnicos, por un lado, y en el desarrollo de la industria editorial y su comercio, por otro ${ }^{13}$. Y quizás fuera así por la presión

\footnotetext{
${ }^{11}$ Véanse, en este mismo volumen, las aclaraciones de Tomàs Martínez Romero, «No han auctoridad de doctrina: Alfonso de Cartagena y sus ideas sobre la tragedia».

${ }^{12}$ Para tomar su pulso me limitaré a mencionar la documentada monografía de Robert Black, $H u$ manism and Education in Medieval and Renaissance Italy. Tradition and Innovation in Latin Schools from the Twelfth to the Fifteenth Century, Cambridge, Cambridge University Press, 2001, quien dedica a Séneca, y en especial a sus tragedias (y a los comentarios de Trevet a las mismas), numerosas páginas. Puede ser útil para una reflexión complementaria el capítulo primero del libro de Anthony Grafton, Defenders of the Text: The Traditions of Scholarship in an Age of Science, 1450-1800, Cambridge, Harvard University Press, 1991.

${ }^{13}$ Me limitaré a citar el libro clásico de Theodore S. Beardsley, Hispano-Classical Translations printed between 1482 and 1699, Pittsburgh, Duquesne University Press, 1970, tan productivo en la labor de los últimos años, y las secciones dedicadas a la traducción de textos greco-latinos en Tomás González Rolán y Antonio López Fonseca, Traducción y elementos paratextuales: los prólogos a las versiones castellanas de textos latinos en el siglo XV, Madrid, Escolar y Mayo, 2014. Especial énfasis cabe hacer en el caso de las Vidas de Plutarco traducidas por Alfonso de Palencia (1424-1492), cuya base textual procede ya de un impreso, en la órbita de la edición latina impresa por Nicolas Jenson en Venecia (1478). Del texto de Palencia, dedicado a Rodrigo Ponce de León, duque de Cádiz, etc., se conoce solo su vida impresa (Sevilla, Paulus de Colonia, Johann Pegnitzer, Magnus Herbst y Thomas Glockner, 2 de julio de 1491, para la princeps, en dos volúmenes). Véase, para más detalles, Susanna Allés Torrent, «Alfonso de
} 
a la que sometía a las prensas castellanas la delantera que Italia, Francia o Alemania habían tomado respecto a otros territorios en la comercialización y distribución de los textos clásicos en latín y griego (que pronto contaron, en los talleres mejor dotados, de personal cualificado para la composición, corrección, revisión o elaboración de materiales auxiliares).

Estas circunstancias, ligadas a la competencia comercial, bien pudieran explicar, siquiera en parte, la prolongada vida impresa de algunos de los ejemplares del Séneca castellano hasta mediados del siglo XVI. Esto es, cómo la imprenta castellana logró imponer y/o adoptó gustos y usos muy concretos de los lectores hispánicos a una forma de acercamiento y proyección de la cultura clásica en tradición indirecta, en versiones que se harían centenarias en pleno auge de un mundo de vertiginosos cambios textuales y editoriales.

Algunas de estas versiones, por otro lado, nos permiten adentrarnos en un campo donde las lindes teóricas son tan importantes como sus consecuencias prácticas, al posibilitarnos trazar continuidades y rupturas entre el régimen manuscrito y el impreso, como resulta paradigmático para el caso de los libros de Séneca de Alfonso de Cartagena, cuyo estudio nos proyecta a una alianza metodológica e histórica entre filología latina, mediolatina y humanística y románica en tradición manuscrita e impresa.

No olvidemos, en todo caso, que, junto a un grueso de novedades editoriales, el último cuarto del siglo XV y la primera mitad del siglo XVI son responsables, en el contexto de la imprenta, de la pervivencia e influencia no solo de textos muy particulares, que de otro modo habrían quedado varados para siempre, como el Amadís de Gaula, sino de completos periodos culturales, como es el de la literatura y el pensamiento del reinado de Juan II de Castilla, cuyo legado encontró en la imprenta el mejor aliado que pudiera esperar ${ }^{14}$.

La obra de abuelos y bisabuelos, al modo en que aparecen las lecturas de Santillana en aquella famosa carta, alimentan el espíritu de los herederos no solo de una cultura, sino de una genealogía o incluso de una específica arqueología del saber, forjada en ámbitos familiares y clientelares, representante

Palencia y la traducción de las Vidas de Plutarco (nuevos datos en torno al texto de partida)», en Cuadernos de Filología Clásica. Estudios Latinos, 28:2 (2008), pp. 99-124 y el primer resultado en forma de libro derivado de su tesis doctoral (aunque el texto que edita no es de Plutarco, como se explica), Las «Vitae Hannibalis et Scipionis» de Donato Acciaiuoli, traducidas por Alfonso de Palencia (1491), Barcelona-Madrid, Brepols, 2014.

${ }^{14}$ Para la historia de Beltenebros, léase Rafael Ramos Nogales, «Amadís de Gaula», en The Arthur of the Iberians: The Arthurian Legend in the Spanish and Portuguese Worlds, ed. de David Hook, Cardiff, The University of Wales Press, 2015, pp. 364-381; para un estudio de caso de los Proverbios de Santillana, muy conectados en la tradición impresa a Séneca y a Alfonso de Cartagena, véase María Morrás, «Fortuna de los Proverbios de Santillana: de la historia del texto a la historia de la recepción», en La escondida senda. Estudios en homenaje a Alberto Blecua, Madrid, Castalia, 2012, pp. 39-62; en especial pp. 53 y 58-59. 
de aspiraciones muy concretas, ya no de académicos y eruditos, sino de las ambiciones de la nobleza castellana (mayor y menor), cuyos designios cristalizarán en una amalgama de literatura y pensamiento que es absolutamente característica del pensamiento de Cervantes ${ }^{15}$.

Se trataba de un modelo cultural híbrido, nutrido por la pedagogía académica, pero que vivía resueltamente extramuros de ella, como ser anfibio. En este modelo era característica la apropiación y el diseño singular de sus marcos de conocimiento como experiencia (por ende de coalición entre las vidas práctica y teórica que se subrayarán en lo más sutil de la producción letrada de la segunda mitad del Cuatrocientos castellano), y su deseo de ingresar en lo nuevo sin desprenderse de lo viejo, de innovar en la tradición, como gustaban decir los maestros de la escuela filológica española. Esta audaz combinación de modelos y enfoques se configuró progresivamente en una suerte de quiasmo cultural que he caracterizado como humanismo escolástico a propósito de Alfonso de Cartagena y, también, del aristotelismo castellano de casi una centuria (digamos que entre 1436 y 1536$)^{16}$.

A través de la resistencia de su obra en la imprenta, investido en los ropajes de Séneca (pero de un Séneca caleidoscópico, como es el medieval) es posible adentrarse en el sentido y orden de la transmisión impresa de un conjunto de textos procedentes de la Castilla de Juan II que tuvieron un fuerte impacto en la España imperial (a ello no es ajeno el aliento último de las ediciones senequianas en Amberes al principio de la década de 1550) que, naturalmente, había de acoger al Séneca hispano como propio, después de su largo sueño peninsular entre los siglos IX al XIV ${ }^{17}$.

${ }^{15}$ Valga recordar la tesis sobre la adopción y adaptación del humanismo en torno a la década de 1440 y, desde luego, la pervivencia y transformaciones de aquel modelo en el futuro, expuesta por Jeremy Lawrance, «Humanism and the Court in Fifteenth-Century Castile», en Humanism in Fifteenth-Century Europe, ed. de David Rundle, Oxford, Society for the Study of Medieval Languages and Literature, 2012, pp. 175-201.

${ }^{16}$ Véase, acaso, Juan Miguel Valero Moreno, «Formas del aristotelismo ético-político en la Castilla del siglo XV», en Aristotele fatto volgare: tradizione aristotelica e cultura volgare nel Rinascimento, ed. de David A. Lines y Eugenio Refini, Pisa, ETS, 2014, pp. 253-310 y «Antecedentes y encrucijadas de la vida activa y contemplativa en la Castilla del Cuatrocientos», en eHumanista, 29 (2015), pp. 32-71.

${ }^{17}$ Sobre la ausencia de Séneca en España en los primeros tiempos y el aspecto medieval de las traducciones ibéricas del siglo Xv, recuérdese lo defendido por Karl Alfred Blüher, Séneca en España. Investigaciones sobre la recepción de Séneca en España desde el siglo XIII hasta al siglo XVII, versión de Juan Conde, Madrid, Gredos, 1983, passim y, por ejemplo: «debemos anotar enfáticamente que, lo mismo que en los siglos XIII y XIV, tampoco en el XV, los monasterios y las pujantes universidades españolas, con Salamanca a la cabeza, parece que hayan desempeñado papel alguno fundamental en la revitalización de Séneca» (p. 119). A estos aspectos ha dedicado Juan Miguel Valero Moreno algunos trabajos, a los que se remite para otras vías de exploración: «Clásicos latinos y clásicos castellanos: un patrimonio textual en su contexto románico», en «Rem tene, verba sequentur». Latinità e medioevo romanzo: testi e lingue in contatto, ed. de Elisa Guadagnini y Giulio Vaccaro, Alessandria, Edizioni dell’Orso, 2017, pp. 7-33; «After Seneca in 


\section{Los cinco libros de Séneca: para una fenomenología del texto impreso}

Son todavía abundantes los misterios por resolver en torno a Los cinco libros de Séneca, su orden, su sentido e incluso su éxito editorial entre los aficionados a la filosofía moral en la primera mitad del siglo XVI.

El texto y su secuencia se ha considerado entre lo último y más imperfecto en el periodo de formación de la tradición manuscrita del corpus senecano con anterioridad a la muerte de su destinatario original, Juan II ( $\dagger$ julio de 1454) ${ }^{18}$. Dicha disposición, bien anterior a la introducción de la imprenta, no pudo pasar sin generar interrogantes tanto a sus receptores más imediatos como a los futuros lectores de este Séneca impreso de 1491 en adelante ${ }^{19}$.

\section{[Alfonso de Cartagena] Cinco libros de Séneca}

Cinco libros de Séneca, Sevilla, Meinardo Ungut y Estanislao Polono, 28 de mayo de 1491, in fol. CICLE 0093; ISTC is00374000; GW M41253

Los V libros de Séneca, Toledo [Sucesores de Pedro Hagembach], 15 de mayo de 1510, in fol. USTC 341740

Los cinco libros de Séneca en romance, Alcalá de Henares, Miguel de Eguía, 28 de enero de 1530, in fol. USTC 341738

Libros de L. A. Séneca, Amberes, en casa de Juan Steelsio, 1548, $8^{\circ}$. USTC 440624

* Libros de L. A. Séneca, Amberes, en casa de Juan Steelsio, 1551, $8^{\circ}$. USTC 440317

Sus primeros impresores, Meinardo Ungut y Estanislao Polono, asentados en Sevilla, difícilmente podían ignorar las inconsistencias que un corpus reducido respecto al proyecto global consolidado en tiempos de Cartagena implicaría en lo que se refiere a las referencias cruzadas que proponen las glosas. En caso extremo, lo que resulta arduo de imaginar es que este aspecto

Spanien. A Reappraisal», en Canon Hispánico. Classical and Late Antique authors in medieval Iberian literature, en prensa; «Alfonso de Cartagena. Historia y filosofía moral en tiempos del emperador Carlos V», en Humanistas, helenistas y hebraistas en la Europa de Carlos V, ed. de Miguel Anxo Pena González e Inmaculada Delgado Jara, Salamanca, Universidad Pontificia de Salamanca, 2019, pp. 119-158.

${ }^{18}$ Véase Georgina Olivetto, Título de la amistança. Traducción de Alonso de Cartagena sobre la «Tabulatio et expositio Senecae» de Luca Mannelli, San Millán de la Cogolla, Cilengua, 2011, p. 82, con referencia a Nicholas Round, «Alonso de Cartagena's Libros de Séneca: Disentangling the Manuscript Tradition», en Medieval Spain: Culture, Conflict and Coexistence. Studies in Honour of Angus MacKay, ed. de Roger Collins y Anthony Goodman, Basingstoke-New York, Palgrave Macmillan, 2002, pp. 123-147.

${ }^{19}$ Para todo lo relacionado con los impresos incunables de textos clásicos en su lengua original o traducción ha de consultarse ahora, necesariamente, el Corpus de Ediciones Incunables de Clásicos Latinos Españoles (CICLE), en línea. Interesa siempre cruzar datos con el área catalana, para lo que se recomienda la consulta de Translat. Base de dades de traduccions al català medieval (1300-1500), [en línea]. 
no fuera notado por los lectores. Y, sin embargo, las impresiones posteriores a 1491 se suceden impávidas, sin que se averigüen enmiendas textuales significativas, y sin que se identifique, como en la princeps, pese a su clara fama, al autor de las traducciones y glosas de los libros de Séneca.

Habría bastado intervenir en el texto con una breve declaración liminar para haber dotado al impreso de una coherencia interna y externa de la que, desde el punto de vista textual, carece.

A tenor de los datos externos e internos que conservamos, sin embargo, pueden proponerse algunas observaciones de sentido común tanto acerca de la labor de los impresores como de la reconstrucción de una lectura crítica por sus inmediatos destinatarios que tenga en cuenta no la entera tradición textual (intangible para los lectores particulares del impreso), pero sí las conclusiones a que estos podrían haber llegado a través de una lectura reactiva al impreso (que pueda luego contrastarse con nuestros actuales conocimientos) ${ }^{20}$.

Para empezar, el lector podía plantearse el porqué de la limitación a cinco libros (supuesto que conociera, lo cual es factible) la existencia del corpus mayor (compuesto de hasta doce unidades). También, el porqué de la disposición concreta del impreso, siendo esta extraña o contraria a la tradición dominante (tipos gamma y delta).

Los cinco libros, pues, han de entenderse como una selección (impuesta si se quiere por un tipo previamente desarrollado en la tradición manuscrita, epsilon). A esta selección, en todo caso, era preciso darle forma y sentido para los lectores del impreso, que podrían coincidir (pero mayoritariamente no), con los lectores de la tradición manuscrita del tipo mencionado o de cualesquiera de los restantes descritos por la crítica filológica. Ofrezco la confrontación entre un testimonio completo del tipo delta (Madrid, BNE, ms. 9613; datado el 15 de marzo de 1461) y la princeps de $1491^{21}$.

\footnotetext{
${ }^{20}$ Véase, en este mismo monográfico, la contribución de Laura Ranero Riestra, «Los Cinco libros de Séneca: del manuscrito al impreso». En el marco del proyecto Alfonso de Cartagena. Obras Completas FFI 2014-55902-P y FFI 2017-84858-P (Ministerio de Economía, Industria y Competitividad - Ministerio de Ciencia, Innovación y Universidades. Gobierno de España) se ha preparado una edición crítica de la fase impresa de los Cinco libros de Séneca, Georgina Olivetto ofrecerá, próximamente, un deslinde en profundidad de la historia de este tipo textual.

${ }^{21}$ Véase Olivetto, ob. cit., pp. 63-64. Las abreviaturas indican S para Séneca y PS para Pseudo-Séneca.
} 
Madrid, BNE, ms. 9613

1. Libro de la vida bienaventurada

(S, De vita beata + De otio sapientis)

2. Libro I de la providencia de Dios (S, De providentia)

3. Libro II de la providencia de Dios (S, De constantia sapientis)

4. Libro I de la clemencia ( $\mathrm{S}$, De clementia I)

5. Libro II de la clemencia (S, De clementia II)

6. Libro de las artes liberales (S, Epistulae morales, LXXXVIII)

7. Libro de amonestamientos y doctrinas (PS, De legalibus institutis)

8. Libro de los remedios contra la fortuna (PS, De remediis fortuitorum)

9. Copilaçión de algunos dichos de Séneca

(Luca Mannelli, Tabulatio Senecce)

10. Libro de las declamaciones

(S, Rhetor, Controversice)

11. Libro de las cuatro virtudes

(Martín de Braga, Formula vitce honestee)

12. *Dichos de Séneca en el fecho de la cavallería

(Vegecio, Epitoma rei militaris)
Sevilla, 1491

1. Libro de la vida bienaventurada

2. Libro de las siete artes liberales

3. Libro de amonestamientos y doctrinas

4. Libro I de la providencia de Dios

5. *Libro II de la providencia de Dios $=$

5.1. Copilaçión de algunos dichos de Séneca

5.2.1. Libro de las declamaciones

5.2.1.2. «Tres hermanas virgenes»

(De beneficiis I, III, 2-5)

Uno de los aspectos más significativos tanto de la tradición manuscrita subyacente como de la impresa es la inclusión de dos tratados fundamentales de Séneca, el Libro de la vida bienaventurada (primero en el orden del impreso) y el Libro I de la providencia de Dios, cuarto de la serie impresa.

Ambos contienen sendos prólogos sobre la «traslaçión» que hacen las veces de apertura, si bien es preciso señalar que todas las evidencias apuntan al prólogo del Primero de providençia como el inicio absoluto del corpus senecanum en cuanto tal corpus y en su constitución más antigua.

La traducción de los libros De la providencia habría sido realizada entre 1431-1432, con el intermedio de la traducción, entre las partes I y II, del Libro de las declamaciones y de los libros II y I De la clemencia. Según Round $^{22}$, que se apoya en evidencias internas, la traducción del libro I De la providencia (De providentia) solo habría estado precedida por la Copilaçión

${ }^{22}$ Round, art. cit., pp. 129-132; Olivetto, ob. cit., pp. 67-70. 
(que en el impreso forma parte del 1lamado, de forma espuria, Segundo libro de providençia de Dios, frente al auténtico, que recogía el texto de De constantia sapientis) y, quizás, pero sin datos ciertos, del Libro de las cuatro virtudes, que el impreso, como su tipo subyacente, eluden.

De la lectura del libro primero de la Providencia podía deducirse su carácter inaugural para el corpus, pero los impresores mantuvieron el desplazamiento a la cuarta posición. La respuesta sencilla es que se limitaron a seguir lo que sugería su manuscrito/s de referencia, esto es, el manuscrito 17798 de la Biblioteca Nacional de España o uno muy próximo a él, como propone Laura Ranero ${ }^{23}$.

La forma que muestra el impreso invita, sin embargo, a pensar en una mínima toma de conciencia de este problema en el orden textual y de lectura. De haber alterado el orden, el lector se habría encontrado de entrada con dos unidades textuales que aparentan sucesión entre ellas, pero que no era posible casar entre sí, pues la correspondencia entre el título del libro II y su contenido no solo no manifestaba continuidad entre uno y otro Libro de la providençia, sino que contraponía un texto estructurado, el libro I, a una colección de fragmentos amparados bajo un mismo epígrafe pero que representaba tres unidades textuales diferenciables, como de hecho, con un generoso espacio en blanco y una rúbrica incontrovertible se evidencia en el impreso para el primer segmento, y luego para el segundo ${ }^{24}$ :

T| Aqui comiença el segundo libro de seneca de la pro|uidençia de dios. En que se tracta commo enel sabidor | no cahe yniuria ni ofensa alguna. Todos estos capitul|los que se siguen fueron sacados de la copilaçion del al|fabeto en el tractado del amor. ${ }^{25}$

[BNE, ms. 19778, f. cxxijr: aqui comiença el segundo libro de sse|neca dela prouidençia de dios enque $\mid$ sse tracta commo enel sabidor non cae $\mid$ jnjuria nin ofenssa aluguna $\cdot$ todos | estos capitulos que sse siguen fueron $\mid$ sacados dela copilaçion del alfabeto | enel tractado del amor.]

[f. (rviiv)] fin del libro segundo dela prouidençia de dios. ॥

[Este explicit no figura en el manuscrito 17798 de la BNE]

Aqui se acaba la vna copilaçion de algunos dichos | de seneca sacados de vuestra grand copilaçion desus di|chos e doctrinas fue hecha e fueron tornados de latin $\mid$ en lenguaie castellano: por mandado del muy alto prin|çipe muy

${ }^{23}$ Descripción detallada del manuscrito en Olivetto, ob. cit., pp. 335-339.

${ }^{24}$ Confronto el texto del impreso con el del manuscrito 17798 de la BNE, con variantes a tener en cuenta. Por lo que respecta a «Tres hermanas vírgenes» el impreso no marca el cambio con una rúbrica, pero destaca esta última sección con una letra capital.

${ }^{25}$ Véase, sobre el Tratado del amor, Olivetto, ob. cit., p. 119. Aquí no ha de entenderse por otra cosa que la Copilaçión, en el sentido «de la copilaçion del alfabeto [que comienza] en el tractado del amor». 
poderoso rey e señor el rey don juan. E no | van situados por ordenaçion por quanto fueron tras|ladados acaso segund que acada vno en leyendo le bien $\mid$ paresçio. E añadieronle las glosas e algunas adiçiones | enlos lugares donde el dicho señor rey mando. $\|$

Aqui eneste quaderno estan algunas declamaçiones | que fueron sacadas en diuersos lugares del original de | las declamaçiones. ||

[BNE, ms. 17798, ff. clxxxiv-clxxxijr: \| aquise acaba la vna copilaçion de algunos | dichos de seneca sacados de vna grande | copilaçion que de sus dichos e dotrinas | fue fecha e fueron torrnados delante $\mid$ en lenguaje castellano por mandado $\mid$ del muy alto prinçipe muy poderoso rey $\mid$ e señor nuestro señor el rey e non van situa|dos por ordenaçion por quanto fueron tras|ladados acaso segunt que acada vno || leyendo le bien paresçio Añadieronle | las glosas e algunas adiçiones enlos $\mid$ logares donde el dicho sseñor rey $\mid$ mando. | | aqui eneste quaderno estan algunas declara|çiones que fueron sacadas de diuerssos $\mid$ logares del original delas declamaçiones.]

Los impresores, a fin de cuentas, mantuvieron el orden de su original, que se abría con un libro con prólogo general y entidad propia, con un texto que completaba al inicial, esto es, el Libro de las artes liberales, al insistir en la importancia del conocimiento y la educación para la vida bienaventurada, y en una colección de sentencias, el Libro de amonestamientos y doctrinas, que fijaba algunos de los contenidos principales de la enseñanza a través de su forma de memorabilia. Los tres primeros libros pueden tener, así, una lectura escalonada o en escalera, de carácter descendente.

Tras ellos se ha situado un significativo corte, un espacio en blanco, que subraya la apuesta visual por una bipartición del libro en dos entidades diferenciables, apoyada también en las rúbricas.

En este caso abre un texto completo con sus prólogos y se cierra, de nuevo, con una colección de excerpta en los que se resumen algunas enseñanzas más o menos reconducibles al libro primero De la providençia de dios (cuyo título recuérdese que hay que entender, en principio, en cuanto derivado de Séneca, desde una perspectiva filosófico moral, no teológico-cristiana). Sin embargo, la consideración que llevó a los compiladores o compilador primero de los cinco libros sí guardaba relación con la asunción cristiana del programa moral senequiano.

La razón por la que el Libro de la vida bienaventurada pudo ocupar la primera posición del conjunto se explica, en realidad, en el prólogo nuncupatorio a Juan II de Castilla, donde se trata de los honores y la gloria mundana como una bienaventuranza a despreciar frente al «soberano bien», «bienandanza perfecta» o «final bienandanza» del camino de virtud que conduce a lo perdurable y la contemplación de Dios, posible gracias a la combinación 
de la «prudencia» y el recto mirar de los «ojos del entendimiento», hábiles a despreciar en primer lugar la soberbia. Se trataba de un programa de filosofía moral que el mismo Cartagena ayudó a fijar y se afirmó en los años en que se compilaron los llamados cinco libros. En el prólogo al Libro de la vida bienaventurada, cuyo tema ocupaba, entonces, uno de los focos de atención de los letraheridos castellanos, se lee:

E aunque en muchos de sus libros Séneca loe la virtud y nos traiga a menospreciar la fortuna, pero principalmente lo hace en este libro que llamó de la vida bienaventurada, donde quiere tratar cuál es nuestro bien soberano. Por ende, entre otros tratados que en vuestro lenguaje mandastes poner, muy con gran razón este es uno para le oír, al fin que la introducción que se sigue dirá.

En este párrafo final del prólogo es preciso entender uno como 'primero' entre los demás o muchos ([...]) libros. Mientras que, sin embargo, y según la cronología establecida por Round, este habría sido, en realidad, el último de los tratados de Séneca en ser traducido por Cartagena, poco después del Libro de las siete artes liberales (mejor Libro de las artes liberales) cuyo contenido, en parte, complementaba, como desde la misma rúbrica argumental se entiende, al de la Vida bienventurada. En las Artes, en efecto, se negaba no ya la gloria y los honores propios de la nobleza y los héroes civiles, sino la propia ambición por el conocimiento como una vía errada para alcanzar el bien supremo ${ }^{26}$. Son aspectos de un debate que quedarían muy bien reflejados, justamente, en un libro de la época de los Reyes Católicos, el Libro de vita beata de Juan de Lucena ${ }^{27}$.

En esta dirección habría tenido más sentido que el espacio del Libro de amonestamientos y doctrinas hubiera sido ocupado por el Libro de los remedios contra fortuna, que hubiese servido quizás de colofón más eficaz a la idea que se desarrollaba en el prólogo del Libro de la vida bienaventurada y que, por otro lado, Cartagena tradujo (el Libro de los remedios, digo), no por caso, al tiempo o inmediatamente después de la Vida bienaventurada ${ }^{28}$.

\footnotetext{
${ }^{26}$ Remito a la edición de Juan Miguel Valero Moreno, «Las Artes liberales de Alonso de Cartagena: los manuscritos salmantinos y el tipo $\alpha$ », en Modelos intelectuales, nuevos textos y nuevos lectores en el siglo XV. Contextos literarios, cortesanos y administrativos. Primera entrega, Salamanca, Seminario de Estudios Medievales y Renacentistas, 2014, pp. 135-213, con las consideraciones y bibliografía que allí se exponen.

${ }^{27}$ Disponemos ahora de una importante edición y revaluación de este texto: Juan de Lucena, Diálogo sobre la vida feliz. Epistola exhortatoria a las letras, ed. de Jerónimo Miguel, Madrid, Real Academia Española, 2014.

${ }^{28}$ Round, art. cit., propuso las siguientes fechas de composición: Libro de la vida bienaventurada (anterior a mayo 1434); Libro de los remedios contra la fortuna (entre mayo y abril de 1434); Libro de
} 
No hemos de olvidar que la transmisión medieval de Séneca encontró lógicas ligazones semánticas y estructurales entre tratados en origen diversos, como muestra la tradición textual del De vita beata y su antigua contigüidad, hasta llegar a la absorción del De otio, como ocurre, en virtud de esta tradición, en la traducción de Cartagena, que presenta un texto dividido en 36 capítulos de los cuales del 1 al 27 corresponden con 27 de las 28 secciones del De vita beata, mientras que del 29 al 36, con los segmentos de De otio. Este sincretismo antiguo de la tradición latina se diluye ya en la tradición romance, tanto manuscrita e impresa, al igual que sucede con la sección final (interrumpida y completa) de la epístola LXXXVIII a Lucilio, dedicada a las artes liberales ${ }^{29}$.

Este asunto, el de la ordinatio, pero también el de una mise en page comparativa de la tradición latina subyacente con la romance, no es en modo alguno episódico, sino que ha de considerarse fundamento de una ecdótica de la materialización del texto.

Cartagena era muy consciente de la importancia de este aspecto, sobre el que aconsejó tanto a Leonardo Bruni como a Decembrio ${ }^{30}$. Así, en la introducción al libro I De la providençia de Dios hace notar que trasladó el tratado «siguiendo el seso ([...]) en nuestro romance. ([...]) E aunque el tratado estaba continuo sin algund partición, partirlo he en capítulos porque mejor y más cierto podáis hallar lo que notar vos pluguiere ([...]) señalelo en los márgenes ([...]) cuanto bastaba a la declaración de la letra». Luego, una preocupación destacada por la legibilidad, estructuración y usabilidad del texto, con una sensiblidad característica de las escuelas que también era muy genuina en un compañero de letras como el Tostado, y por la que ya había mostrado particular empeño Enrique de Villena en su proemio a la Eneyda ${ }^{31}$.

amonestamientos y doctrinas (entre la primera mitad de 1434 y con posterioridad a julio de 1435).

${ }^{29}$ Véase Georgina Olivetto, «Observaciones preliminares para una edición crítica del Libro de la vida bienaventurada», en Literatura medieval y renacentista en España: lineas y pautas, ed. de Natalia Fernández Rodríguez y María Fernández Ferreiro, Salamanca, Seminario de Estudios Medievales y Renacentistas y Sociedad de Estudios Medievales y Renacentistas, 2012, pp. 783-790; y Valero Moreno, ob. cit.

${ }^{30}$ Se verán ejemplos en las cartas enviadas por Alfonso de Cartagena a Pier Candido Decembrio en 1438 (n. ${ }^{\circ}$ VIII) y 1456 (n. ${ }^{\circ}$ XVII), editadas y traducidas por Tomás González Rolán, Antonio Moreno Hernández y Pilar Saquero Suárez-Somonte, Humanismo y teoría de la traducción en España e Italia en la primera mitad del siglo XV, Madrid, Ediciones Clásicas, 2000.

${ }^{31}$ Sobre partición, puntuación y otras señales textuales se extiende Enrique de Villena en las glosas 108-113 del prohemio de su traducción de la Eneida (aunque los copistas de los testimonios conservados no siguen, en general, sus instrucciones); véase en Enrique de Villena, Traducción y glosas de la Eneida, ed. de Pedro M. Cátedra, Salamanca, Biblioteca Española del siglo XV-Diputación de Salamanca, 1989, 1, pp. 33-35; en cuanto al Tostado, véase Emiliano Fernández Vallina, «Líneas e historias: un problema de crítica textual a propósito de Eusebio de Cesarea y san Jerónimo en el siglo xv castellano», en $\mathrm{eHu}$ manista, 6 (2006), pp. 88-99. 
Esta atención a los detalles se refleja en un cuidado tanto por las formas de transmisión del saber como por el cotejo textual propiamente dicho que se destaca, justamente, en el «Prólogo en la traslaçión» del libro I De la providençia de Dios, el tratado que habría de ir al frente del corpus senecano (aunque no en el tipo epsilon, como ya hemos dicho), y donde se habla de la versión previa de una colección de sentencias por la que se había interesado el rey.

Este, el último de los V libros de Séneca, bajo el título de Libro II de la providençia de Dios, resultaba ser, como no podía dejar de ser advertido, la Copilaçión. Es el texto más complejo y peculiar del corpus. De inicio parecía destinado al uso privado de Juan II, que deseaba penetrar el texto de esta compilatio, esto es, la Tabulatio Senecce de Luca Mannelli. En la Copilaçión el tú comunicativo entre rey y letrado y la guía establecida para las glosas conferían al texto un carácter privado, que no se revisó al ser incorporado al corpus mayor. La Copilaçión era en sí misma una selección muy parcial de un texto de grandes dimensiones ordenado alfabéticamente por Mannelli, del que se toman tanto texto como glosas (que hay que cuidar de no confundir con las del propio Cartagena, elaboradas con alguna posterioridad y señaladas unas veces sí, pero otras veces no, bajo la forma de Adición) ${ }^{32}$. Por demás, el libro II De la providençia en los impresos no solo incluye la llamada Copilaçión, como vimos, sino también el Libro de las declamaçiones y un final extravagante que procede de un pasaje del De beneficiis ${ }^{33}$.

El lector atento de los impresos debía llegar a esta conclusión a través de fragmentos diseminados y de las rúbricas de enlace. Por ejemplo, en el Prólogo en la traslación:

aunque habés gran familiaridad en la lengua latina y para vuestra conformación bastaba leerlo como lo escribió, pero quisistes haber algunos de sus notables dichos en vuestro castellano lenguaje ([...]). E como de algunas copilaciones nuevas que de las obras de Séneca muchos en uno ayuntaron vos pluguiesen algunos dichos, mandastes a mí que los tornase en nuestro lenguaje, no por la orden que ellos estaban escritos mas como a caso vinieren. E porque aquellos eran cortados por el copilador según a su propósito entendió

\footnotetext{
${ }^{32}$ Nótese, por otro lado, que no es extraño que Cartagena interpole con observaciones propias las glosas traducidas de Mannelli.

${ }^{33}$ Sobre el Libro de los amonestamientos véase Jorge Fernández López, «Las Declamaciones de Séneca traducidas por Alonso de Cartagena: edición y estudio», en Cuadernos de Filología Clásica. Estudios Latinos, 33:2 (2013), pp. 329-380. Analiza muy oportunamente el excerptum de De beneficiis, clave para la delimitación de la historia textual de corpus senecano de Alfonso de Cartagena, Georgina Olivetto, «La collatio externa: en el principio era el códice», en Incipit, 31 (2011), pp. 13-33 (en concreto, pp. 20-22).
} 
que cumplía, quisistes ver algunos otros sacados enteramente de su original, e escogistes entre todos el libro que se llama De la Providencia ([...]) el primero se debe leer aquél que habla de Dios que es el primero principio.

Como es meridiano, la posición inaugural del libro I De la providencia parecía incontestable en su origen y parece trazar una parábola hacia el prólogo del Libro de la vida bienaventurada que cerraría este círculo especulativo y hermenéutico, aunque en los impresos el orden se muestre invertido.

En el marco de la transmisión manuscrita, el hecho de que un copista se atuviera a su modelo si no disponía de otro podía servir de justificación a las incongruencias textuales. En el marco de la transmisión impresa, la selección de un original de imprenta dispuesto para ser multiplicado parecía exigir mayores atenciones que hicieran una mínima justicia a la voluntad de quien concibió su trabajo con mayor rigor.

Cartagena, en efecto, había mostrado una notable atención al error textual, como muestra una significativa glosa del Libro de amonestamientos y doctrinas (De legalibus institutibus) sobre El que ama: «[...] por error de los escribanos. Ca en el vuestro libro dize 'vix' ([...]). E según esta letra fue aquí trasladado, y en otro libro dice 'jus', que quiere decir derecho, y según esta letra debía ser trasladado así [...]». Es decir, Cartagena cotejó los textos latinos de Juan II con otros de su posesión o a los que tuvo acceso, y tuvo buen cuidado de no conceder a compilaciones como la Tabulatio el mismo rango, ni textual ni interpretativo, que a los textos de tradición directa. También enmendó ope ingenii, como en una Adición donde se matiza: «La glosa suso escrita ([...]). Mas porque a mí pareció que el texto no dice aquello trasladelo según el entendimiento que a mi juicio la letra quería. ([...]) la glosa ([...]) el glosador lo entendía. Mas no conviene desta traslación la cual va continuando este texto en el comienzo del capítulo» (Copilaçión, «En el tratado De la injuria»).

En fin, esta sección textual comprende un gran número de glosas, y el mayor aparato de referencias internas y cruzadas con respecto al resto de los libros. Pero, al estar desconectadas de su orden y propósito original (el de la Tabulatio) quedan, en esencia, relegadas a un uso disminuido ${ }^{34}$. Por otro lado,

\footnotetext{
${ }^{34}$ De hecho, en el «prólogo en la traslación» al libro I De la providencia, se insiste en el carácter cortado, fragmentario, de la misma Tabulatio y del tenor de florilegio de la selección castellana, motivo por el cual el propio rey quiso «ver algunos otros sacados enteramente de su original». La traducción de estos otros favorecerá la conexión de numerosas referencias de la Copilaçión con sus textos íntegros, como es el caso de De clementia (que no se incorpora a los Cinco libros, sin embargo), aunque deja fuera de juego otros tan sustanciales como De beneficiis, además de los tratados consolatorios, las tragedias y el corpus general de las epístolas de Séneca. En todo caso, los enlaces rotos en el texto castellano (cfr. «Averigua.
} 
la ordinatio del impreso mantiene de forma ambigua la inconsistencia de su portada, que ya se manifiesta en la rúbrica misma de esta sección al indicar: «En que se trata cómo el sabidor no cae injuria ni ofensa alguna. Todos estos capítulos que siguen fueron sacados de la copilación del alfabeto en el Tratado del Amor»». La segunda advertencia desdice el título otorgado por el libro a este capítulo, pero más grave es, si cabe, que la rúbrica se inicie con el argumento del libro que en verdad habría correspondido, es decir, el libro II De la providencia de Dios, no otro, a ojos de Cartagena, que su traslado de De constantia sapientis, cuyo argumento era, en efecto, el indicado en la rúbrica: «nec iniuriam nec contumelliam accipere sapientem».

Todos los detalles importan, puesto que la ordinatio de un manuscrito como el 9613 invita a pensar en una toma de conciencia muy distinta del corpus en la que, con independencia de la cronología de la traducción, se ha establecido una jerarquía textual por la que se agrupan los textos cuya autoría senecana es indiscutible, y cuyo carácter discursivo es orgánico, frente a aquellos otros que, aunque Cartagena mismo atribuye a Séneca, solo han de ser vinculados a este en cuanto a su tradición textual, que así los transmite de manera ininterrumpida, con pocas excepciones, hasta los tiempos de Erasmo. La lectura y trascendencia de los Cinco libros habría sido muy distinta si se hubiera concretado en la edición de los cinco primeros textos del manuscrito 9613 u otro similar: Libro de la vida bienaventurada, Libros I y II De la providencia, De la clemençia y Artes liberales.

Estos dislates, junto a la escasa calidad textual de numerosos pasajes, «Isidoro» por «Hesiodo», por ejemplo, en el Libro de las artes liberales (pero casos similares abundan) fueron probablemente el motivo de que el libro gozara de una fortuna más bien limitada, a pesar de su pedigrí original, en relación a sus compañeros de viaje, los Proverbios glosados por Pero Díaz de Toledo y la traducción, incompleta, de las Epístolas morales.

([[...]]) Esto cata en el tratado De la pena en el capítulo que comienza «verdadera», en la glosa que dice que Apio fue privado del juzgado y matose a sí mismo en la cárcel») podían suponer un problema para un lector cualquiera, pero no para su destinatario inicial, Juan II, que siempre podría recurrir a su «gran compilaçión» («sacados de vuestra »: la Tabulatio). Por otro lado, nótese, desde el punto de vista de la cronología interna, cómo en la glosa Regulo de la selección final de las Declamaciones se advierte sobre el hecho de encontrarse ya traducido el libro primero De la providencia, con amplia glosa: «De la victoria deste Regulo dejo aquí de decir porque está en vuestro libro de la Providencia de Dios en el capítulo VIII, por ende no se repite». Es, en realidad, el capítulo VII en los Cinco libros. Para el lector del impreso esta glosa, si se atiende solo a la división mayor de la portada, situaría la versión De la providencia como anterior a la de la Copilaçión (aunque en realidad estamos en las Declamaciones). 


\section{Intersecciones}

Es significativo, entonces, frente a esta falta de autoridad textual, que la imprenta salmantina, alma mater de Alfonso de Cartagena, no se hiciera eco de estos Vlibros de Séneca, o que un impresor atento como Antón de Centenera en Zamora, se decantara por los Proverbios de Pero Díaz de Toledo o por textos escolares como la Ecloga de Teodulo o el De legendis antiquorum libris sive de liberalibus studiis (esto es, el texto de Basilio Magno según la traducción latina de Leonardo Bruni), pero no por la obra de Cartagena. Y, al contrario, sorprende que un editor de cierta finura intelectual, como Miguel de Eguía, apostara por reimprimir esos cinco libros en Alcalá de Henares ya en 1530. Las razones textuales no eran, sin embargo, prioritarias.

La historia del Séneca hispano no puede desligarse, en todo caso, de los ámbitos especializados en que va a ser recibido y cuyas condiciones históricas y culturales han de ser barajadas a la par que las circunstancias específicamente textuales.

Todavía a finales del siglo xv, entonces, la Atenas castellana, Salamanca, universidad de referencia del Reino, apenas disponía de una biblioteca digna de llamarse por ese nombre ${ }^{35}$. Esto es, lo que entendemos por una biblioteca institucional, centralizadora de los saberes y distribuidora de los mismos y sus inercias. Por la misma época, una biblioteca regia, como la estudiada en detalle por Elisa Ruiz para Isabel la Católica, es más una biblioteca personal o, por mejor decir, familiar, que una biblioteca estatal, como la que concebirá mucho más adelante Felipe $\mathrm{II}^{36}$. Algunos nobles y familiares atesoran significativas bibliotecas en Castilla, pero las más ricas ofrecen inventarios numéricamente pobres, en comparación con la trascendencia de su uso y las noticias que nos proporcionan. Fundaciones religiosas y colegios acumulan, de manera dispersa, el grueso de los saberes almacenados en los libros ${ }^{37}$. Pero este saber, aunque pueda usufructuarse extramuros es, en cierta medida, invisible, y solo se traslada bajo garantías de préstamo muy condicionadas, y con el mayor celo posible, a personajes de relevancia, con todas las reticencias respecto a su futuro regreso.

\footnotetext{
${ }^{35}$ Véase Benigno Hernández Montes, Biblioteca de Juan de Segovia. Edición y comentario de su escritura de donación, Madrid, Consejo Superior de Investigaciones Científicas, 1984. Una buena puesta al día histórica de la biblioteca universitaria de Salamanca se hallará en Scripta. Tesoros manuscritos de la Universidad de Salamanca, Salamanca, Universidad de Salamanca, 2017.

${ }^{36}$ Elisa Ruiz García, Los libros de Isabel la Católica: arqueología de un patrimonio escrito, Salamanca, Instituto de Historia del Libro y de la Lectura, 2004.

${ }^{37}$ Mencionaré solo el libro misceláneo de Isabel Beceiro Pita, Libros, lectores y bibliotecas en la España medieval, Murcia, Nausícaä, 2007, remitiendo a la bibliografía que ahí se repertoria.
} 
Esta situación escurridiza del libro, y el carácter etéreo de las bibliotecas en tanto que red de conocimiento accesible, cambió paulatinamente con el desarrollo de la copia y su mayor distribución y difusión a lo largo de los siglos XIII, XIV y XV, lo que explica que en la segunda mitad del Cuatrocientos una cultura literaria con tradición textual romance, tan limitada como sabemos que es la castellana ${ }^{38}$, pudiera generar no menos de una treintena de copias en volúmenes más bien densos no de una obra original (en latín o castellano), sino una traducción de las obras de Séneca como la que proveyó Alfonso de Cartagena a los castellanos por el consabido encargo de su rey Juan II.

La estructuración de este corpus, cuya esfera pública es, sobre todo, la curia, la nobleza letrada y los funcionarios en torno a las nuevas estructuras de un incipiente estado, no se entendería, sin embargo, sin su fermentación en el ambiente del studium, para el caso el salmantino, donde se generaron entonces las fuerzas centrífugas que unieron el renovado interés por los autores clásicos con el acmé del estudio conjunto de la teología y la filosofía moral en Castilla que, derivados ambos de sus innegables modelos escolásticos de los siglos XIII y XIV, de carácter europeo, iban a confluir en renovadas perspectivas en lo que toca a la transmisión textual y del pensamiento.

En este contexto, y a pesar de su escaso arraigo peninsular en época antigua (siglos IX al XII) de Séneca y su obra, del corpus formado por Cartagena podemos decir que, en términos relativos, se difundió como la pólvora, sin parangón con otros textos castellanos de similar tipología.

En ningún lugar de Europa una versión romance de un autor clásico tuvo la acogida y la continuidad del corpus de Cartagena, sobre el cual se vertebró un interés que se extendió a otros romanceamientos (fundamentalmente dos) que pronto fueron incorporados al Reino a través de la introducción del invento de la imprenta en Castilla, aproximadamente una década más tarde que los primeros impresos europeos. Ha de hablarse siempre en términos relativos, de nuevo, debido a la escasez de la primera hornada, pero sin desdeñar su carácter pionero en relación a la consolidación de Séneca como producto editorial diversificado y vinculado claramente a estrategias comerciales y no solo culturales.

En este sentido, la apuesta de los impresores establecidos en Castilla por un Séneca vernáculo, sin duda como respuesta a una demanda explícita o intuida, carece de equivalente, por su calado, en las regiones que como Italia, Alemania y Francia fueron motores de los grandes proyectos editoriales.

${ }^{38}$ Como puso de relieve Alberto Blecua, «Los textos medievales castellanos y sus ediciones», en Romance Philology, 45:1 (1991-1992), pp. 73-88. 
La etapa incunable y postincunable, que en España solemos fijar hasta 1520, y que coincide en los años de la segunda década con una completa reestructuración de los saberes de la que es paradigma Erasmo (también en lo que a Séneca se refiere) resulta extraordinariamente feraz en tanteos y experimentos textuales en los que todavía pueden identificarse las fuerzas del pasado en las dinámicas que conducen al futuro.

A través del artificio de la imprenta, los ideales de los reinados de Juan II y Enrique IV encontraron nueva vida y una presencia fértil primero hasta la muerte de Fernando el Católico y la clausura política de aquel reinado transformador, y luego también en la época del Emperador, sobre todo hasta mediados de los años 30, momento a partir del cual aquellas tradiciones textuales y editoriales comienzan a declinar en todos los sentidos y a adquirir una deriva arqueológica o extravagante.

En las primeras décadas, en todo caso, entre 1482 y 1512, la imprenta y el tráfico que acarrea han conectado a los hombres nuevos con las nuevas y viejas ideas. Es entonces cuando es posible que la biblioteca particular de un solo hombre, la de Hernando Colón, supere en entradas e importancia a la biblioteca dinástica del reino y que cuente, además, con un catálogo profesional, diríamos que mercantesco, de sus ejemplares ${ }^{39}$. La imprenta acicateó el coleccionismo, la consideración nueva del libro como una propiedad privada, acompañada en la vertiente editorial de la lucha por el establecimiento de derechos comerciales. La accesibilidad e inmediatez del libro impreso rivalizaba con las limitaciones de expansión del manuscrito, incluso a pesar de su producción en serie y en materiales cada vez más asequibles.

Este hecho, el de la posesión individual y su estratificación en segmentos diferenciables de la sociedad alfabetizada parece banal (a nadie se le oculta), pero resulta en cualquier caso decisivo en lo que se refiere a la selección y transmisión de las tradiciones textuales que asume la imprenta.

Para muchos, esto es, Séneca estuvo por primera vez a su alcance (en el texto y en la lengua): reconozcamos que esa oportunidad no habría existido, con el mismo peso, sin la imprenta. Pero claro es también que cuando existió consenso entre los impresores, como es el caso del Séneca castellano, los textos recibidos distaban no ya de sus originales latinos, sino también de sus modelos vernáculos, como ocurre con el Séneca de Cartagena, sin que

\footnotetext{
${ }^{39}$ Catalogue of the library of Ferdinand Columbus. Reproduced in facsimile from the Unique Manuscript in the Colombine Library of Sevilla, ed. de Archer M. Huntington, Nueva York, The Hispanic Society of America, 1905 y Hernando Colón, Abecedarium B y Supplementum, Madrid, Fundación Mapfre-Cabildo de la Catedral de Sevilla, 1992; Tomás Marín Martínez, José Manuel Ruiz Asencio y Klaus Wagner, Catálogo concordado de la biblioteca de Hernando Colón, Madrid, Fundación Mapfre Cabildo de la Catedral de Sevilla, 1993-1995, 2 vols.
} 
mediara una reflexión (como la polémica surgida en Italia en torno a Petrarca, por ejemplo) en cuanto al texto adoptado.

El caso del Séneca hispano es paradigmático, sin duda, pero en absoluto único. Cuando el propio Miguel de Eguía (Logroño, 1529) se decidió a imprimir el Libro de Marco Polo, lo hizo ya en una traducción que asumía una tradición claramente derivativa.

Ese origen marginal es el de los textos que son objeto de esta reflexión. Los cinco libros de Séneca, impresos en Sevilla (1491) expresaban el consenso con un tipo de la tradición manuscrita del corpus senecano que era, como hemos visto, el menos afortunado.

Por su parte, los Proverbios de Séneca glosados por Pero Díaz de Toledo, para Juan II de Castilla, parecen responder a una tradición textual italiana, representada también en el ms. Q-I-8 de El Escorial, como apuntó Round en su tesis doctoral (1967) y mantuvo luego en un trabajo de 1972 donde trata de la difusión de los llamados Proverbia Senecae ${ }^{40}$.

Naturalmente, aquí nos las habemos con un Séneca en gran medida espurio, pues el modelo del texto es en realidad la compilación (Sententice Seneca) de sentencias del mimógrafo latino Publilio Siro, del que proceden 247 entradas, más 118 del pseudo senecano De moribus, que suman 365 (un aforismo y su glosa para cada día del año, según la idea ya pergeñada por Enrique de Villena para sus glosas a la Eneida). Pero no es posible por ello desvincular el texto de la idea de un Séneca hispano por cuanto fue recibido como tal.

Este Séneca que no es Séneca gozó de excelente salud editorial, equiparándose la cifra de impresos conocidos, once, a la de manuscritos supervivientes, doce, en un último censo ${ }^{41}$.

\footnotetext{
${ }^{40}$ Nicholas G. Round, «The Mediaeval Reputation of the Proverbia Seneca: A Partial Survey Based on Recorded mss.», en Proceedings of the Royal Irish Academy: Archaeology, Culture, History, Literature, 72 (1972), pp. 103-151; véase p. 111, n. 16. No se discute aquí el repertorio de impresos y manuscritos propuesto en su tesis doctoral por José Luis Herrero Prado, Edición y estudio de la vida y obra de Pero Díaz de Toledo, señor de Olmedilla, Madrid, Universidad Nacional de Educación a Distancia, 1991, vol. 1, pp. 119-150; y edición parcial de los textos en vol. 2, pp. 1197-1232. Los datos son tomados en buena parte de la tesis doctoral de Barbara Ann Riss, Pero Díaz de Toledo's «Proverbios de Seneca»: an annotated edition of Ms. S-II-10 of the Escorial Library, Berkeley, University of California, 1979.

${ }^{41}$ Véase Carlos Roldán Donoso, «La intervención del impresor sobre la obra: Pedro Hagenbach y su edición de los Proverbios de Séneca (Toledo 1500)», en Revista de Estudios Latinos, 15 (2015), pp. 113-140. Cfr. la relación que ofrece Round, art. cit., p. 103. Añado algunos detalles respecto a los impresos y ofrezco un listado comparativo, a manejar con la debida precaución, de ediciones incunables de los Proverbia extractadas del ISTC. En este mismo catálogo encontraremos las primeras ediciones, con notable tradición propia, de textos como el De remediis fortuitorum [Colonia, Impresor de Dares, 1472, in $4^{\circ}$ (texto exento)] o De quattuor virtutibus cardinalibus sive De formula honestce vitce (más De remediis) [Venecia, Imprenta de Juvenal, $c$. 1470, in $8^{\circ}$ ]. Son títulos bien presentes entre varios de los impresores de los Proverbia. Para una impresión hispana del De moribus véase [Zaragoza, Pablo Hurus y Juan Planck,
} 


\section{Impresos castellanos de los Proverbios de Pero Díaz de Toledo}

Zamora, Antón de Centenera, 3 de agosto de 1482, fol.

Zaragoza, [Juan Hurus], 10 de febrero de 1491, $4^{\circ}$.

Sevilla, Meynardo Ungut y Estanislao Polono, 22 de octubre de 1495, fol.

Toledo, Pedro Hagenbach, 10 de febrero de $1500,4^{\circ}$.

Sevilla, Juan Pegnitzer y Magno Herbst, 18 de febrero de 1500 , fol.

Sevilla, Jacobo Cromberger, 20 de abril de 1512 .

Sevilla, Jacobo Cromberger, 7 de septiembre de 1528 .

Sevilla, Jacobo Cromberger, 1535.

Amberes, Juan Steelsio, 1552.

Medina del Campo, Guillermo de Millis, véndense en casa de Adrian Ghemart 1552.

Medina del Campo, Guillermo de Millis, 1555, a costa de Adrian Ghemart ${ }^{42}$.

\section{Impresos latinos de los Proverbia}

Roma, Johannes Gensberg, no antes de 1475.

Roma, Bartholomaeus Guldinbeck, c. 1477.

Ulm, Johann Zainer, c. 1486-1492.

Roma, Stephan Planck, c. 1487.

París, Georg Mittelhus, c. 1488-1493.

Venecia, Johannes Baptista Sessa, 1489.

Leipzig, Conrad Kachelofen, c. 1489-1490.

Roma, Stephan Planck, c. 1488-1490.

Deventer, [Ricardis Pafraet], 1490-1491.

París, Georg Wolf, c. 1491-1492.

París, Antoine, Caillaut, c. 1493.

Brescia, Bernardinus de Misintis, [1494-1496]

[Speyer, Conrad Hirst, c. 1495]

Deventer, [Ricardus Pafraet], 1495.

[París, Franciscus de Guaschis de Stradella, $c$. 1498]

[París, Pierre Le Dru], c. 1498.

[París, Antoine Caillaut, c. 1498]

[Colonia, Cornelis de Zierikzee, c. 1500]

\footnotetext{
c. 1480-1484], $4^{\circ}$, en romana (uno de los dos ejemplares en España, que guarda la Real Biblioteca, sig. $\mathrm{I} / 145$ (1), se encuentra digitalizado).

${ }^{42}$ Siguen a los Proverbios las Amonestaciones y doctrinas de Séneca en traducción de Alfonso de Cartagena, no identificadas en su autoría por Cristóbal Pérez Pastor, La imprenta en Medina del Campo, Madrid, Establecimiento Tipográfico «Sucesores de Rivadeneyra», 1895, n. ${ }^{\circ} 124$, p. 135, pero sí en Blüher, ob. cit., p. 148, n. 105; cfr. Morrás, art. cit., p. 58. La edición de 1555 es otro estado de la de 1552, como señala Pedro M. Cátedra en su introducción al facsímil del libro de Pérez Pastor, Salamanca, Junta de Castilla y León, 1992, p. 32.
} 
Si contamos solo la lista de impresos hasta 1535 , la proporción de estos Proverbios frente a los Cinco libros de Séneca fue de 8 a 3, dato que puede considerarse significativo para la producción del periodo. Y, desde luego, nos habla también de públicos y usos diferenciados o diferenciables que consuenan, más allá de nuestras fronteras, con lo que sucedía en Europa, donde se diseminaron los impresos de los Proverbia, la mayor parte de ellos sin glosas, $\mathrm{y}$, por lo tanto, con cabida en pequeños impresos o amalgamados con otros textos. El texto de Pero Díaz de Toledo, con sus abundantes comentarios, constituía, sin embargo, una variación llamativa y propiamente hispánica ${ }^{43}$.

Por su parte, la versión parcial de las Epístolas de Séneca vinculada o atribuida a Fernán Pérez de Guzmán, convivió en su origen con otras adaptaciones peninsulares que, sin embargo, no entraron en competencia editorial con ella, pues fueron descartadas por la imprenta. Esta traducción procede, en última instancia, de una versión italiana (redacción II) que, aunque realiza cotejos con el texto latino para resolver algunos problemas del texto, depende de una versión italiana anterior (redacción I) que, a partir del antiguo texto francés (1308-1310), se realizó en lengua toscana a instancias de Riccardo Petri $(c .1312-1313)^{44}$ :

\footnotetext{
${ }^{43}$ Aunque no es la primera ni la única traducción con o sin glosas en Europa. Véase Round, art. cit., pp. 133-135 y Georgina Olivetto y Hugo O. Bizzarri, «Los Proverbios de Séneca llamados vicios y virtudes», en «De ninguna cosa es alegre posesión sin compañía». Estudios celestinescos y medievales en honor del profesor Joseph Thomas Snow, coord. de Devid Paolini, Nueva York, Hispanic Seminary of Medieval Studies, 2010, 2, pp. 228-251, en particular, p. 230. Para un recorrido de la fortuna de los

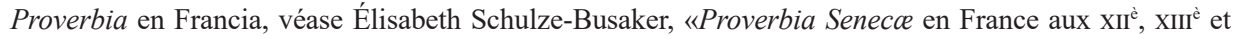
XIV ${ }^{\grave{~}}$ siècles», en La traversée européenne des Proverbia Seneca: de Publilius Syrus à Erasme et au-delà, coord. de Marta López Izquierdo, Nancy, Presses Universitaires de Lorraine, 2013, pp. 109-128. Datos para un contexto más amplio en Giovanni Borriero, «Sénèque le rhéteur, Sénèque, (Pseudo)-Sénèque», en Translations médiévales. Cinq siècles de traductions en français au Moyen Âge (XI⿳亠丷厂犬十 $X V^{\dot{e}}$ siècles), ed. de Claudio Galderisi, Turnhout, Brepols, 2011, pp. 220-230.

${ }^{44}$ Mario Eusebi, «La più antica traduzione francese delle Lettere morali di Seneca e i suoi derivati», en Romania, 91 (1970), pp. 1-47; censimento de 48 manuscritos de las tres redacciones conocidas y scheda con bibliografía en Cristiano Lorenzi Biondi, «Pistole di Seneca», en DiVo. Dizionario dei Volgarizzamenti [en línea]. Para el texto vinculado a Fernán Pérez de Guzmán véanse los detalles tratados en Andrea Zinato, «Volgarizzamenti delle Epistulae morales di L. A. Seneca e loro diffusione nella penisola iberica», en Annali di Ca' Foscari, 31 (1992), pp. 371-390, en especial pp. 376-381, así como «Fernán Pérez de Guzmán e le glosse alla traduzione medievale castigliana delle Epistulae morales ad Lucilium: un itinerario filologico e filosofico», en Annali di Ca' Foscari, 34 (1995), pp. 403-427; una revisión de la tradición, con propuesta de stemma general, en Tomàs Martínez Romero, «Conexiones románicas: las versiones castellanas de las Epistolas de Séneca (BNE 8852)», en Revista de Filología Española, 94:1 (2014), pp. 175-208, en especial pp. 198-200; para un ágil estudio del conjunto de las versiones ibéricas, Elisa Ruiz García, «En torno a los romanceamientos de Séneca en el Cuatrocientos», en Seneca: una vicenda testuale, ed. de Teresa De Robertis y Gianvito Resta, Florencia, Mandragora, 2004, pp. 65-82. En el primer cuarto del Trecento pueden datarse las Epistole morali volgarizzate en autógrafo de Andrea Lancia, versión parcial y compendiada de las epístolas 4, 8-88 y 37, que se conservan en un manuscrito de la Biblioteca Comunale degli Intronati de Siena, ms. C III 25. Para la bibliografía de las versiones
} 
E fizo las trasladar [las Epistolas] de latín en lengua florentina Ricardo Pedro, ciudadano de Florencia, a utilidad y corrección de todos los que este libro leerán, las quales son trasladadas del original del dicho Séneca por la orden que en él fueron falladas. Y estas que aquí se siguen fizo trasladar de lengua toscana en el romance de nuestra España Fernán Pérez de Guzmán.

Esta traslación del tipo II de la lengua francesa a la italiana, fuera advertido o no por el traductor castellano, suponía la asimilación de procedimientos que no eran extraños en la tradición manuscrita, más bien inquieta que pasiva a este respecto. La traducción castellana de las Epistolas que ahora nos interesa, conservada en 9 testimonios manuscritos y en cuatro impresos anteriores a 1535, refleja un corpus de 75 epístolas en una secuencia no continua.

\section{[Fernán Pérez de Guzmán], Epistolas}

Epístolas, Zaragoza, [Pablo Hurus] a expensas de Juan Tomás Favario, 3 de mayo de 1496.

Las epistolas de Séneca, Toledo, Pedro Hagenbach, 1502.

Las epístolas de Séneca, Toledo, s. n., 1510.

Epistolas de Séneca en romance, Alcalá de Henares, Miguel de Eguía, 15 de enero de 1529.

Epístolas familiares de Lucio Anneo Séneca, nuevamente traduzidas en castellano. Summa de Philosophía moral compuesta por [[...]] Leonardo Aretino, Amberes, en casa de Juan Steelsio, 1551.

En este caso, no solo la versión castellana se vincula al texto en tercer grado de la tradición italiana; además, el primero de los impresos, atribuido a Pablo Hurus (Zaragoza, 1496), se estampó a expensas de un ciudadano italiano, Juan Tomás Favario de Lumelo, procedente de Pavía ${ }^{45}$.

Este Juan Tomás Favario fue un importante agente cultural, responsable de otros impresos como la Historia troyana (en traducción de Pedro Núñez Delgado; Pamplona, Arnao Guillén de Brocar) o del Laberinto de Fortuna de Juan de Mena en Sevilla (Meinardo Ungut y Estanislao Polono), ambos de 1496, o en la misma imprenta sevillana y el mismo año, del Hieronymus

francesas, Giovanni Borriero, «Sénèque», en Translations médiévales. Cinq siècles de traductions en

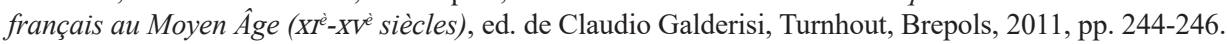

${ }^{45} C f r$. Denis E. Rhodes, «Italy and Spain in the Fifteenth and Sixteenth Centuries: Connections in the Book Trade», en La memoria de los libros. Estudios sobre la historia del escrito y de la lectura en Europa y América, dir. de Pedro M. Cátedra y María Luisa López-Vidriero, ed. de María Isabel de Páiz Hernández, Salamanca, Instituto de Historia del Libro y de la Lectura, 2004, 1, pp. 319-326; en particular pp. 320-321. 
(trad. desconocido). En Castilla financió a Andrés de Burgos para la impresión en 1505 de las obras de Juan del Enzina, y son obras que dependen de él trabajos impresos en distintos talleres y lugares como el Espejo de conciencia (Toledo, Gaspar de Ávila, 1525), la Crónica sarracina de Pedro del Corral (Valladolid, Nicolás Terri, 1527), un Valerio Máximo (Alcalá de Henares, Miguel de Eguía, 1529) o el Libro primero del invencible cavallero don Clarián de Landanís (Medina del Campo, Pedro de Castro, 1542).

El interés de Favario por las Epistolas de Séneca, tan ajeno en principio al de otros títulos en los que intervino, parece más bien financiero que cultural y, por lo tanto, reflejo de una intuición comercial de aquellos textos que podían funcionar mejor en un mercado tan particular como el ibérico. Pero no todo lo explica el beneficio. Favario había acudido en esta ocasión a uno de los impresores más dotados para la edición de textos latinos, clásicos y medievales, como Pablo Hurus de Constanza. Por medio del uso económico de una misma portada, con ligeras modificaciones, en la que un sabio presenta a un rey su libro, Hurus supo dotar de una mínima homogeneidad a un programa de clásicos: la Ethica ad Nicomachum en la versión de Bruni $(1492)^{46}$, el Salustio de Francisco Vidal de Noya (1493) y las Epistolas (1496). El clasicismo gótico de su portada lo recogerá de manera emblemática Jorge Coci, también en Zaragoza (1509), para la portada del Laberinto de Fortuna, con el sencillo expediente de cambiar los nombres de Nero y Séneca por los del rey don Juan y Juan de Mena.

El favor del que gozó la versión castellana de las epístolas puede contrastarse con la menor difusión del volgarizzamento italiano del humanista Sebastiano Manilio, Pistole del moralissimo Seneca, que eleva su prefacio a Ludovico Sforza, duque de Milán (Venecia, Sebastiano Manilio y Stefano y Bernardino de' Nalli, 14 de abril de 1494, in fol.), del que la BNE cuenta con dos ejemplares ${ }^{47}$. En el periodo incunable, pues, Castilla podía proponer una versión no desdeñable de parte del corpus de las Epístolas, seleccionada de entre una tradición manuscrita muy entroncada con la europea francesa e italiana y prácticamente pionera en cuanto al Séneca vernáculo impreso ${ }^{48}$. Por

\footnotetext{
${ }^{46}$ Recuérdese que ya antes había impreso la Ethica de Aristoteles (Zaragoza, c. 1489, $4^{\circ}$ ) en la versión romance del «egregio bacheller de la Torre». Se recomienda, para el juego de portadas, la comparación con la del Seneca de quattuor virtutibus cardinalibus, Impr. de Historia S. Albani, 1474, cuya reproducción se puede consultar en la Biblioteca Digital de la Universidad de Coimbra.

${ }^{47}$ Para esta figura, cuya actividad estuvo estrechamente ligada a la imprenta, véase Sara Centi, «Sebastiano Manilio», en Dizionario Biografico degli Italiani, 69 (2007) [en línea].

${ }^{48}$ Compárese con el siguiente listado, de ediciones latinas previas, procedentes del ISTC, al que añado luego otro de las Opera, con distintos estados de concreción textual, por cuanto estas solían ir acompañadas también de las epístolas: a) París, Au Soufflet vert, 1475; Roma, Arnoldus Pannartz, 1475; Zwolle, Peter van Os, 1480-1481; Leipzig, Arnoldus de Colonia, 1493; París, [Pierre le Dru], 1494-1495;
} 
su parte, el corpus senecano de Alfonso de Cartagena, si bien en su vestidura textual menos cuidada, no desdecía, sino que adelantaba cronológicamente y mejoraba en no pocos aspectos, aquello de lo que en su lengua pudieron disponer los franceses a través de Les ouvres de Senecque en la vieja traducción atribuida a Laurent de Premierfait (c. 1380-1418) impresa por Antoine Vérard (París, s. d., entre 1499-1503, in fol.) ${ }^{49}$.

La imprenta llega tarde a Castilla (Sinodal de Aguilafuente, Segovia, Juan Parix, 1472). Impresores de origen germánico, francés e italiano traen ingenios, tipografías, tacos y otros elementos característicos de sus ambientes de origen. Pero pronto se adaptarán al panorama peninsular para evitar, entre otras cosas, la competencia con las imprentas europeas, lo que explica su especialización en el producto vernáculo tanto catalán como castellano y luego portugués.

En este sentido, la impresión de décalage que produce el predominio de la tipografía gótica, en vez de la romana, en la imprenta española hasta mediados del siglo XVI, debe ser valorada con atención. Algunos de los primeros incunables castellanos fueron impresos no en la gótica de inmediato habitual, sino en caracteres romanos similares a los italianos, extendiéndose luego, sin embargo, la primacía de la fundición de tipos góticos.

Las derivas editoriales marcaron pues, el aspecto y la composición en el molde de los textos, por lo que se impone la consideración de un paso a dos entre la bibliografía material y/o la filologia a stampa y el estudio inmanente de las tradiciones textuales, sin que ninguno de los enfoques pueda prescindir del otro.

Que la adopción textual del Séneca hispano en la imprenta sea fundamentalmente acrítica, desde el punto de vista filológico, respecto a la tradición manuscrita, no significa que los impresos deban rechazarse como deteriores $\mathrm{o}$ acaso descripti de sus modelos. Para bien o para mal los textos impresos acabaron por configurar una tradición propia y una recepción lo suficientemente

Leipzig, Arnoldus de Colonia, 1495; Leipzig, Wolfgang [Stöckel], 1497; Colonia, Cornelis de Zierikzee, etc., 1494; b) Nápoles, Mathias Moravus, 1[4]75; Treviso, Bernardus de Colonia, 1478; Venecia, Bernardinus de Choris, etc., 1490; Venecia, Bernardinus de Coris, 1492; Venecia, Johannes y Gregorius de Gregoriis, 1492.

${ }^{49}$ Contiene seis piezas correspondientes a: De remediis fortuitorum, De brevitate vitce, Epistulae (I$X V)$, De quattuor virtutibus cardinalibus, Epistulce Pauli Seneca, De moribus. He consultado el ejemplar de la Biblioteca Nacional de Austria en Viena, sig. Ink 26.E.27. Sobre Laurent de Premierfait, véase el volumen colectivo dirigido por Carla Bozzolo, Un traducteur et un humaniste de l'époque de Charles VI: Laurent de Premierfait, París, Publications de la Sorbonne, 2004; para Vérard, Masami Okubo, «Antoine Vérard et la transmission des textes à la fin du moyen âge», en Romania, 125 (2007), pp. 434-480; y Mario Eusebi, «Les lettres à Lucilius de Sénèque dans un imprimé d'Antoine Vérard», en Le Moyen Français, 51-53 (2001-2003), pp. 249-261. 
diversa como para que su examen textual pueda y deba considerarse de forma autónoma. Operaciones como la de Petrocchi al editar la Commedia secondo la volgata, con eliminación de amplias fases de la historia del texto, según el modelo más convencional de la filología clásica, deben advertirnos sobre los privilegios concedidos a determinados segmentos históricos de la recepción.

Recibido: 6/05/2018 Aceptado: 19/07/2018 


\section{$\cos$}

\section{LOS IMPRESOS CASTELLANOS DE SÉNECA Y SU CONTEXTO EUROPEO}

RESUMEN: En este trabajo se pretende revaluar y contextualizar la historia impresa de Séneca en España a partir de tres versiones que gozaron de fortuna en el entramado editorial castellano hasta aproximadamente 1550: los Proverbios de Séneca, con la glosa de Pero Díaz de Toledo, Los cinco libros de Séneca, en versión de Alfonso de Cartagena, y las Epístolas de Séneca vinculadas a la figura de Fernán Pérez de Guzmán. En relación a estos textos ha sido parcialmente estudiada su tradición manuscrita, pero se ha prestado poca atención a los rasgos específicos de su tradición impresa. A través del estudio de elementos textuales, culturales y editoriales se pretende trazar una aproximación a este corpus paradigmático.

Palabras Clave: Cultura impresa. Séneca. Traducción. Alfonso de Cartagena. Pero Díaz de Toledo. Fernán Pérez de Guzmán.

\section{Seneca's Early Printed Books in Castile and its European ConteXt}

ABSTRACT: In this paper we try to assess and to put in context the printed history of Seneca in Spain through three versions that enjoyed fortune in the Castilian editorial framework until around 1550: the Proverbs of Seneca, with the comment of Pero Díaz de Toledo, The five books of Seneca, in Alfonso de Cartagena's version, and the Seneca Epistles linked to Fernán Pérez de Guzmán. In relation to these texts, its manuscript tradition has been partially studied, but little attention has been paid to the specific features of its printed tradition. Through the study of textual, cultural and editorial elements, we intend to draw an approximation to this paradigmatic corpus.

Keywords: Print Culture. Seneca. Translation. Alfonso de Cartagena. Pero Díaz de Toledo. Fernán Pérez de Guzmán. 